\title{
Shape-controlled Synthesis of Gold Nanoparticles by a Green Approach
}

\section{R. Herrero-Calvillo and Gerardo Rosas}

\section{Universidad Michoacana de San Nicolás de Hidalgo, Morelia, Michoacan de Ocampo, Mexico}

Nanomaterials have been studied widely due to their unique properties provided by their high surface energy and quantum confinement. There are many types of nanoparticles; among them, there are nanoparticles composed of noble metals, such as gold and silver, and they have many applications in the field of environmental biology, electronics, and catalysis [1]. Gold nanoparticles (AuNPs) stand out mainly for their easy reduction and difficult oxidation, providing excellent chemical stability during their applications in catalysis. One of the most used methods for AuNPs obtaining is the chemical reduction method, which is a very efficient method that is carried out by two steps. The first step consists in the reduction of metal ions to their zero-valent form, and the second step is the stabilization of the growing particles. However, the biological applications of the nanoparticles synthesized by this method are very limited because the reducing agents are dangerous to many biological systems, and thorough washing is required [2]. Therefore, the implementation of synthesis alternatives that generate the least possible amount of harmful substances is justifiable. A highly sustainable nanoparticle synthesis method is green synthesis. It takes advantage of the antioxidant properties of some biological organisms, such as fungi, plants, and bacteria. Also, these organisms contain organic surfactants that work as stabilizing agents []ㅡ. Due to the wide variety of compounds in plants, it is not very easy to control the size and morphology of synthesized AuNPs. However, it is possible to formulate experiments that can determine the specific conditions for the obtaining of AuNPs with well-defined size and shape [4].

In this research, an experimental study was carried out using aqueous extract of Loeselia mexicana at different concentrations in order to control the morphology of the obtained AuNPs. The extract was made by mixing $8 \mathrm{~g}$ of leaf powder with $100 \mathrm{ml}$ of water at $70{ }^{\circ} \mathrm{C}$ for $10 \mathrm{~min}$ with magnetic stirring. The synthesis was carried out by mixing 5,20 , and $80 \mathrm{mg} / \mathrm{ml}$ of leaf extract with $2 \mathrm{mM} \mathrm{HAuCl} 4$ at $40^{\circ} \mathrm{C}$ until a stable color change was obtained. The obtained AuNPs were monitored by UV-Vis spectroscopy to verify the formation of nanometric particles. The morphology and size were analyzed by SEM and TEM.

After 25 min of reaction, a color change from yellowish to purple was observed, indicating the formation of AuNPs. Figure 1(a) shows the UV-Vis spectra, wherein the characteristic SPR peak of quasi-spherical AuNPs is shown. The appearance of an SPR peak at a longer wavelength is also observed, indicating the formation of different morphologies. The $5 \mathrm{mg} / \mathrm{ml}$ sample had the highest absorbance and a second peak between 700 and $800 \mathrm{~nm}$. The $20 \mathrm{mg} / \mathrm{ml}$ sample had a lower absorbance peak and another between 800 and $900 \mathrm{~nm}$. This indicates the generation of a higher amount of AuNPs of different morphologies and a smaller amount of quasi-spherical AuNPs. The $80 \mathrm{mg} / \mathrm{ml}$ sample only showed the appearance of the characteristic peak of quasi-spherical AuNPs.

On the other hand, Figures 1(b)-(d) correspond to the SEM images. Figure 1(b) shows the presence of large triangular and truncated triangle morphologies. Also, Figure 1(c) shows the presence of smaller triangles. Figure 1(d) shows the presence of only quasi-spherical AuNPs. Figure 2 corresponds to the bright-field TEM images. Figure 2(a) corresponds to the sample of $5 \mathrm{mg} / \mathrm{ml}$, wherein the coexistence of the different morphologies can be seen. It can be seen that the triangles are flat by having a smaller and uniform contrast compared to the AuNPs. Also, Figure 2(b) shows the $80 \mathrm{mg} / \mathrm{ml}$ sample, wherein the presence of only AuNPs is observed. 
In summary, it was observed that at a low extract concentration, the stabilizers are not able to cap all AuNPs, allowing the generation of flat triangles. When the concentration is higher, it is possible to obtain AuNPs with only one morphology. However, an optimal maximum concentration must be found, since an excess of extract carries out the interference of the migration of reduced ions, resulting in the reduced formation of AuNPs.
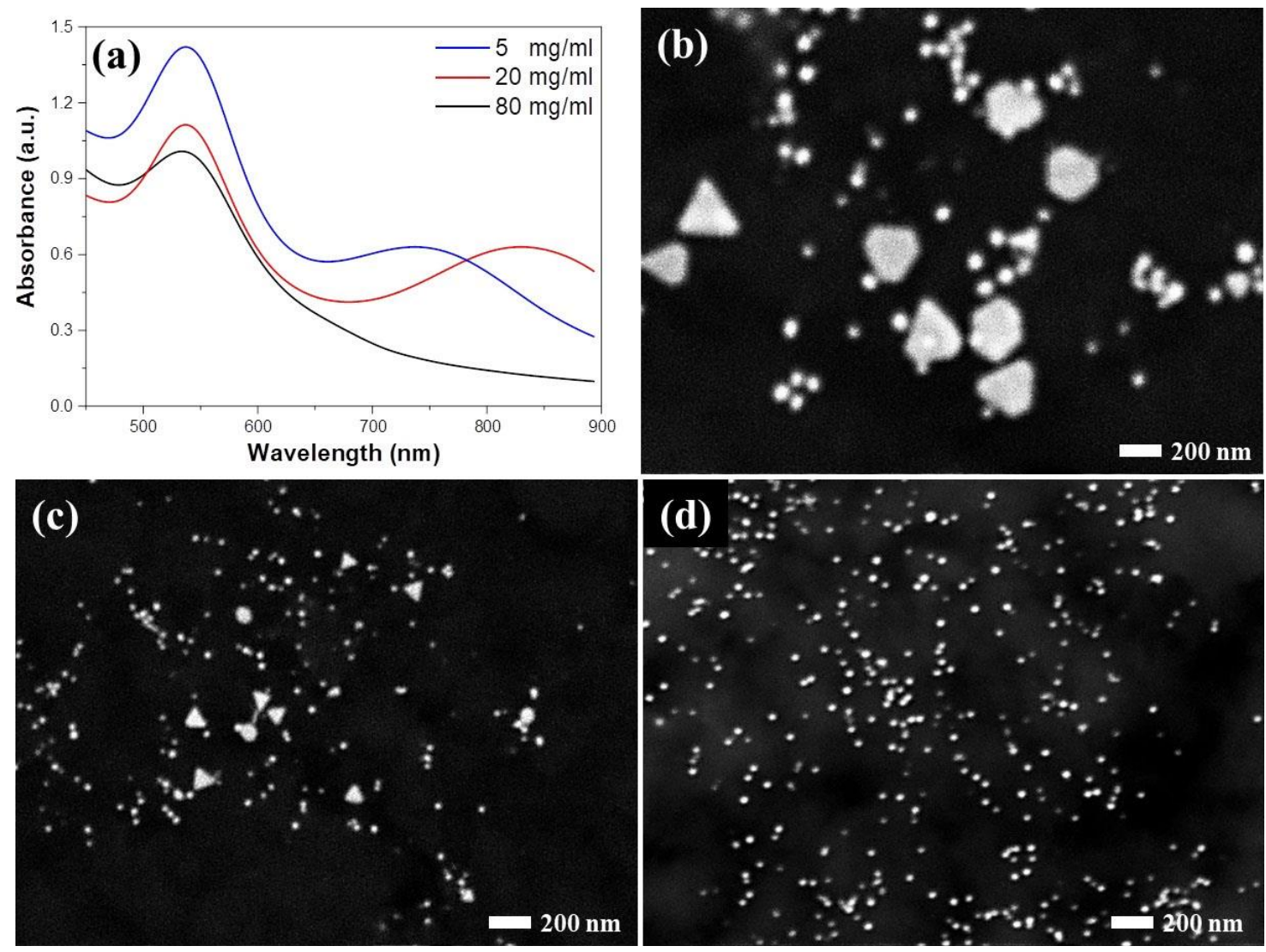

Figure 1. (a) UV-Vis spectra, SEM images of (b) $5 \mathrm{mg} / \mathrm{ml}$, (c) $20 \mathrm{mg} / \mathrm{ml}$, and (d) $80 \mathrm{mg} / \mathrm{ml}$ samples
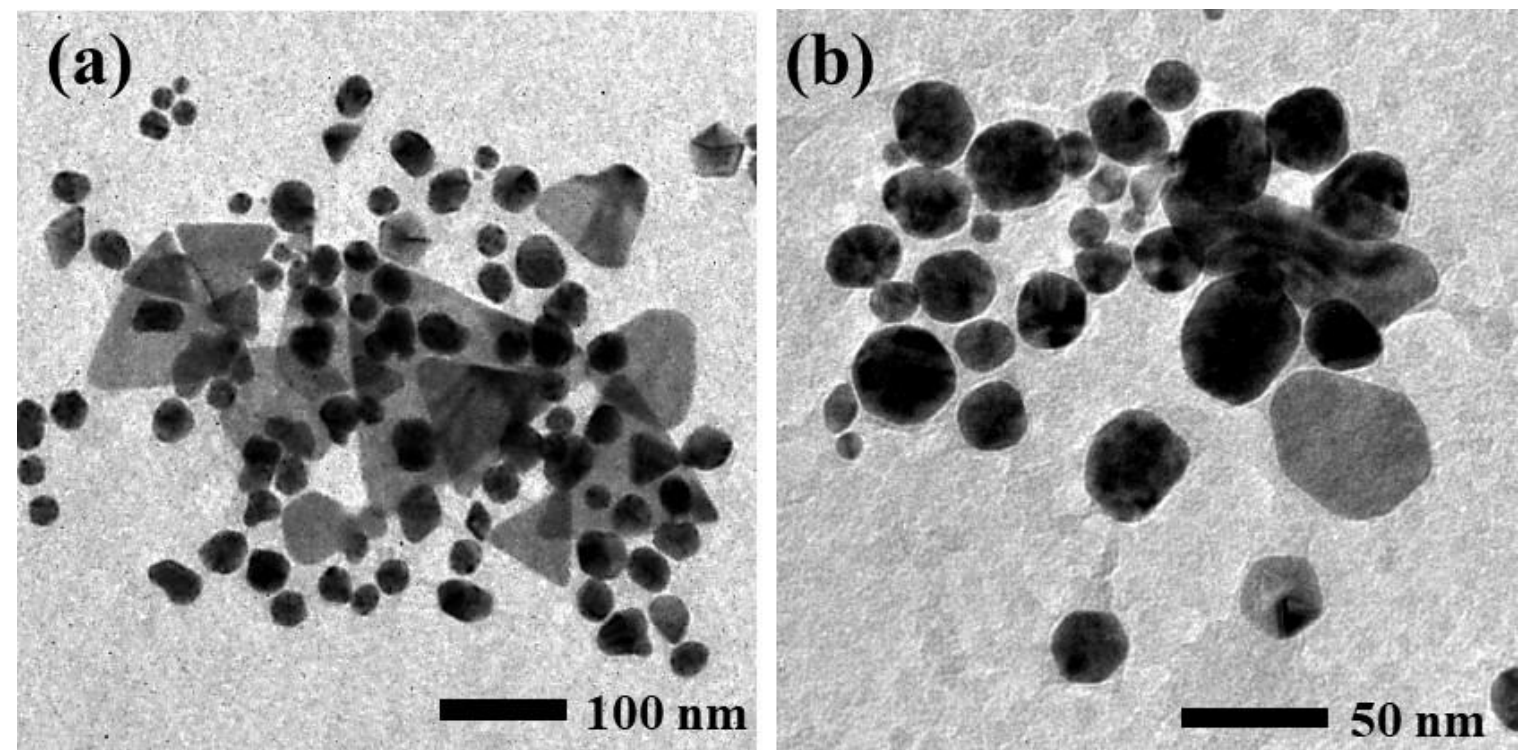

Figure 2. TEM images of (a) $5 \mathrm{mg} / \mathrm{ml}$, and (b) $80 \mathrm{mg} / \mathrm{ml} \mathrm{samples}$ 


\section{References}

1. Khan, A.U., et al., Recent progress of algae and blue-green algae-assisted synthesis of gold nanoparticles for various applications. Bioprocess and biosystems engineering, 2019. 42(1): p. 1-15.

2. Siddiq, A.M., et al., Green (gemini) surfactant mediated gold nanoparticles green synthesis: Effect on triple negative breast cancer cells. Nano-Structures \& Nano-Objects, 2019. 19: p. 100373.

3. Kumar, I., et al., Green one-pot synthesis of gold nanoparticles using Sansevieria roxburghiana leaf extract for the catalytic degradation of toxic organic pollutants. Materials Research Bulletin, 2019. 117: p. $18-27$.

4. Ankamwar, B., M. Chaudhary, and M. Sastry, Gold nanotriangles biologically synthesized using tamarind leaf extract and potential application in vapor sensing. Synthesis and Reactivity in Inorganic, Metal-Organic and Nano-Metal Chemistry, 2005. 35(1): p. 19-26. 